\title{
Representação de apego materna, relação mãe- criança e apego inseguro do filho: um estudo qualitativo
}

Maternal attachment cepresentations, mother-child
relationship and child's insecure attachment: a qualitative
study

\section{Las madres con representaciones de apego sin base segura e hijo apego inseguro}

\section{Marcela Bortolini*}

Universidade Federal do Rio Grande do Sul - UFRGS, Porto Alegre, Rio Grande do Sul, Brasil

\section{Cesar Augusto Piccinini**}

Universidade Federal do Rio Grande do Sul - UFRGS, Porto Alegre, Rio Grande do Sul, Brasil

\begin{abstract}
RESUMO
O padrão de apego materno com os seus próprios cuidadores tende a influenciar suas relações posteriores, em especial a relação mãe-filho. Esta expectativa, baseada na literatura, norteou o presente estudo que teve 0 objetivo de investigar as experiências, o apego da mãe com seus cuidadores e o apego inseguro do filho. Participaram duas díades mãe-filho em que a criança apresentava comportamentos de apego inseguro [selecionadas em uma amostra de 63 participantes]. As mães responderam instrumentos que avaliavam os cuidados recebidos; suas representações de apego; sua relação atual mãe-filho e os comportamentos de apego da criança. Os resultados revelaram consistências entre os cuidados recebidos pouco sensíveis, não incentivadores da autonomia, mães com representações de apego sem base segura e comportamentos de apego inseguro do filho. Estes resultados apoiam a literatura e apontam para a importância de avaliações e intervenções precoces, visando evitar a transmissão intergeracional do padrão de apego inseguro.
\end{abstract}

Palavras-chave: apego inseguro, representação, relações, mãe-filho.

\section{ABSTRACT}

Maternal attachment with their own caregivers tends to influence their later relationships, especially the mother-child relationship. This expectation, based on the literature, guided present study that aimed to investigate mother's experiences, mother's attachment with her caregivers and child's insecure attachment. Two mother-child dyads participated, in which the child had insecure attachment behaviors [selected in a sample of 63 participants]. The mothers answered instruments that evaluated care received; 
representations of attachment; mother-child relationship and the child's attachment behaviors. The results revealed consistency between the care received little sensitive, non-autonomy incentives, maternal insecure attachment and child's insecure attachment behaviors. These results support the literature and point out the importance of early evaluations and interventions to avoid the intergenerational transmission of insecure attachment pattern.

Keywords: insecure attachment, representation, relation; mother-child.

\section{RESUMEN}

El objetivo de este estudio fue investigar las experiencias de la madre con sus cuidadores y el apego inseguro del niño. Ellos asistieron a dos parejas madre-hijo en el que el niño mostró comportamientos de apego inseguro. Las experiencias de las madres con sus cuidadores fueron investigados por una serie de percepciones de los cuidadores ya través de sus representaciones de apego; mientras que la proporción actual de diadas se investigó a través de una entrevista. Los resultados revelan consistencias entre las experiencias de las madres con pequeños cuidadores sensibles y no partidarios de la autonomía y el comportamiento actual de apego inseguro de su hijo. Estos resultados apoyan la literatura sobre la relación entre las experiencias maternas con sus cuidadores, la relación en la sala de maternidad con el niño y el tipo de apego del niño.

Palabras clave: apego inseguro, la representación, relaciones, madre-hijo.

A criança, por meio da relação que estabelece com seus cuidadores, representa internamente suas experiências, o que ela espera do mundo, a maneira como a mãe e outras pessoas significativas poderão se comportar, bem como o que ela espera acerca dela mesma e das interações (Bowlby, 1989). Essa organização psicológica foi nomeada de "modelo de funcionamento interno" por Bowlby (1988/1989) e também tem sido pesquisada através do conceito de script (Waters, Rodrigues, \& Ridgeway, 1998). Script foi definido como representações mentais mais específicas, nas quais o apego estaria representado e guardaria crenças sobre as relações familiares. Pesquisadores da Teoria do Apego tem destacado a importância desse conceito para compreender os vínculos formados ao longo do desenvolvimento, especialmente nas relações filiais (Waters et al., 1998, Waters \& Rodrigues-Doolabh, 2001; Waters \& Waters, 2006).

Especificamente acerca das representações de apego inseguro, estas tenderiam a estar relacionadas, particularmente, às rupturas de vínculos parentais, como por exemplo, perda, abandono, falecimento, os quais teriam impactos considerados transcendentes ao desenvolvimento individual, de modo a instaurar um padrão internalizado de funcionamento e de interação (Fonagy, 1999). Entretanto, apesar destas vivências estarem associadas à formação de representações de apego sem base segura, a maneira que essa experiência seria reparada ou elaborada seria o ponto de predição 
das características do desenvolvimento vincular e afetivo (Fonagy, 1999). Nesse sentido, mães com vivências de rupturas não reparadas ou elaboradas, teriam representação de apego sem conteúdo de base segura e um histórico de capacidade de resposta menos sensível aos sinais de seus filhos, os quais tenderiam a não utilizá-las como uma base segura tanto em situações comuns, quanto de emergência (Bost et al., 2006; Veríssimo, Monteiro, Vaughn, Santos, \& Waters, 2005). Considerando tais aspectos, existiria uma inter-relação entre a experiência inicial de apego com os cuidadores principais, a representação ou script de apego, os comportamentos parentais na relação pais-filho e o padrão de apego do filho (van ljzendoorn \& Bakermans-Kranenburg, 1997; Muzzio, Muñoz \& Santelices, 2008). Tais relações foram evidenciadas em estudos empíricos que verificaram semelhanças entre padrões de apego dos pais e padrões de apego dos filhos (Fonagy, Steele \& Steele, 1991; Grossmann \& Grossmann, 2011; van Ijzendoorn, 1995; van Ijzendoorn \& Bakermans-Kranenburg, 1997; Wong et al. 2011).

Em relação aos comportamentos parentais, Parker, Tupling e Brown (1979) postularam dois domínios. Um dos domínios contemplou a presença de afeto, calor emocional disponibilidade, sensibilidade e a ausência de frieza e rejeição; e o domínio de superproteção foi caracterizado pela presença de controle e intrusão, e ausência de encorajamento da autonomia. Segundo Ainsworth et al. (1978), mães com crianças com apego inseguro seriam não responsivas, apresentariam pouco contato físico e responderiam de maneira inconsistente aos sinais das crianças. Nesse sentido, um vínculo menos adequado na infância, característico do apego inseguro, seria caracterizado por falta de afetividade, de disponibilidade, de sensibilidade e de encorajamento da autonomia, e estaria relacionado com um desenvolvimento emocional menos saudável na vida adulta. Dessa forma, o apego inseguro, tema central deste estudo, estaria associado à dificuldade materna de reconhecer e responder pronta e eficazmente a angústia do seu bebê e suas necessidades (Ainsworth et al., 1978).

Para além dos comportamentos parentais, outros aspectos que influenciariam o desenvolvimento dos padrões de apego inseguro nas crianças seriam contextos com muitas dificuldades familiares, relações amorosas conturbadas entre os pais e cuidadores que não lidam bem, por exemplo, com pressões no trabalho, pais com quadros emocionais clínicos, como depressão e ansiedade, comportamentos hostis, menos sensibilidade e mais comportamentos intrusivos nas interações com os filhos (Main, 2000; Miljkovitch, Pierrehumbert \& Halfon, 2007; Moehler, Brunner, Wiebel, Reck, \& Resch, 2006; Kaitza, Maytala, Devora, Bergmana \& Mankuta 2010). Além disso, o temperamento da criança poderia acarretar diferentes 
reações nos cuidadores, afetando a relação mãe-bebê e consequentemente o padrão de apego da criança (Leekers, 2011).

Dessa maneira, pautando-se nas representações mentais de apego, nos comportamentos parentais e nas características das crianças, van Ijzendoorn e Bakermans-Kranenburg (1997) propuseram um modelo, no qual salientaram que a representação de apego seria formada com base nas experiências iniciais de apego e por relações posteriores, inclusive as atuais; que as experiências passadas de apego poderiam ser ressignificadas pela representação mental atual de apego, influenciando os comportamentos parentais e a construção de novas relações de apego; que um bom amigo, cônjuge ou psicoterapeuta poderia proporcionar uma "base segura" para resignificar experiências adversas da infância; o comportamento dos pais seria influenciado pelo contexto social, visto que a rede de apoio social pode moderar os efeitos de circunstâncias desfavoráveis; e algumas crianças poderiam tornar mais difícil para que os pais fossem sensíveis, devido a deficiências físicas graves ou temperamento altamente irritável. Assim, os padrões de apego contemplariam diversas variáveis individuais, relacionais e contextuais que poderiam influenciar o relacionamento da criança com os genitores.

No estudo de Bortolini e Piccinini (2015) os autores apresentaram evidencias sobre a associação entre a experiência de mães com seus cuidadores e o apego seguro de seus filhos. Seguindo um delineamento semelhante ao utilizado no presente estudo, os resultados revelaram que as mães que tiveram percepções de um bom cuidado na infância ou que conseguiram elaborar registros emocionais negativos na adultez, e tiveram representações de apego com base segura tinham um apego seguro com seu filho. Essas mães apresentavam recursos emocionais para lidar com as necessidades emocionais dos seus filhos, o que deve ter contribuído para os comportamentos de apego seguro dos seus filhos.

Pelo exposto acima, considera-se que a capacidade de uma mãe atender as demandas emocionais do seu filho de maneira a suprir as necessidades de conforto, proteção e incentivo da autonomia, estaria associada a sua própria história de vinculação na infância e ao longo da vida. Entretanto, a literatura vem investigando a que características maternas o apego do seu filho está mais relacionado (Huth-Bocks, Levendosky, Bogat \& von Eye, 2004; Mikulincer, Hirschberger, Nachmias \& Gillath, 2001; Waters \& Waters, 2006). No presente estudo, as representações de apego maternas, entre outras dimensões, foram priorizadas para compreender esta dinâmica. Diante disso, conhecer as características das díades que apresentam apego inseguro, se torna relevante, visto que é por meio dessa relação que o desenvolvimento psíquico individual se desenvolverá. Diante disso, buscou-se investigar as experiências e o apego da mãe com seus cuidadores, e o apego inseguro do filho. Com base na 
literatura que destaca a transmissão dos padrões de apego ao longo do desenvolvimento (Bolwby, 1989; Waters \& Rodrigues-Doolabh, 2001) a expectativa foi de que as representações de apego maternas sem base segura estivessem associadas a relação mãe-criança pouco sensível e aos comportamentos de apego inseguro da criança.

\section{Método}

\section{Participantes}

Participaram do estudo duas díades mãe-bebê cujos bebês apresentavam comportamentos de apego inseguro, avaliados pelo Attachment Q-sort (Waters, 1987). No Caso 1, a mãe Paula tinha 37 anos e a filha Paola, 2 anos e 1 mês; enquanto no Caso 2, a mãe Beatriz tinha 32 anos e a filha Bruna, 2 anos ${ }^{1}$. As crianças apresentavam comportamentos de apego menos seguro com escores 0,244 e 0,226, respectivamente (numa escala que vai de 0 a 1), o que as colocava no extremo inferior entre as crianças com apego menos seguro dentre as 63 avaliadas, que integravam o estudo maior intitulado "Impacto da creche no desenvolvimento socioemocional e cognitivo infantil: estudo longitudinal do sexto mês de vida do bebê ao final dos anos pré-escolares" - CRESCI (Piccinini et al., 2012) ${ }^{2}$. Todas as díades moravam com o pai e a mãe da criança em Porto Alegre e eram de nível socioeconômico médio. Todas as participantes assinaram o Termo de Consentimento Livre e Esclarecido (TCLE).

Delineamento, Procedimento e Instrumentos

Foi realizado um estudo de caso múltiplo (Stake, 2006), com o objetivo de investigar qualitativamente as experiências da mãe com os seus cuidadores e a relação atual mãe-filho em duas díades, cujos filhos tinham comportamento de apego inseguro. Seguindo os procedimentos do projeto $\mathrm{CRESCl}$, as famílias foram contatadas via telefone e/ou e-mail. Para aquelas que concordaram em participar, foram agendados dois encontros individuais com a mãe, de aproximadamente uma hora e trinta minutos cada, na universidade ou em outro local de sua escolha. Para fins de coleta de dados as mães responderam os seguintes instrumentos: (1) Ficha de dados sociodemográficos da família (CRESCl, 2011): utilizada para obter informações da configuração de moradia, situação profissional, renda da família, entre outros dados familiares. (2) Attachment Q-Sort/AQS (Waters, 1987): usado para avaliar os comportamentos de apego da criança. É composto de 90 itens, que a mãe responde em uma escala likert de 1 (totalmente parecido) a 7 (totalmente diferente). A correlação entre os resultados pontuados e o protótipo da criança 
segura (valor critério estabelecido por especialistas na área) permite que se obtenha um perfil da criança num contínuo que pode variar entre -1 e +1 (correlação perfeitamente negativa ou positiva com a criança segura ideal), conforme detalhado por Waters (1987). Escores baixos indicam apego menos seguro e os altos apego mais seguro. Para facilitar a leitura, no presente estudo, se usou o termo apego inseguro e apego seguro, como sinônimo dos termos propostos pelos autores. A versão utilizada foi traduzida para o português e utilizada por Barbisan (1993). (3) Parental Bonding Instrument/PBI (Parker, Tupling, \& Brown, 1979): usado para avaliar a percepção materna a respeito dos cuidados recebidos de seus pais/cuidadores. É uma escala composta de 25 itens, respondidos em uma escala likert que varia de 1 (muito parecido) a 7 (muito diferente). O instrumento avalia dois eixos, o afeto (afeto, calor, disponibilidade, cuidado, sensibilidade versus frieza e rejeição) e a superproteção dos pais (controle, intrusão versus encorajamento da autonomia), classificando os pais em uma de quatro categorias: cuidado ótimo; controle afetivo; controle sem afeto e cuidado negligente. O PBI foi adaptado para o português por Hauck et al. (2006). (4) Attachment Script Assessment/ASA (Waters \& Rodrigues-Doolabh, 2001): usado para avaliar a presença de um script, ou representação materna de apego de base mais ou menos segura. Para aplicação são usadas cinco folhas de papel, cada uma contendo um título e uma lista de palavras distribuídas em três colunas e se solicita que a pessoa elabore uma narrativa. Duas das histórias são adulto-criança ("A manhã do bebê" e "Consultório do médico"), outras duas histórias são adulto-adulto ("O acampamento de Joana" e "Pedro e o Acidente de Suzana") e uma quinta, considerada neutra visto que não entra na análise ("A manhã de compras"). As quatro narrativas são posteriormente analisadas em termos de coerência, conhecimento e acesso do script de base segura. Cada narrativa recebe um escore de 1 (script sem conteúdo de base segura aparente) a 7 (script com conteúdo de base segura com elaboração substancial), sendo o escore final a média das quatro histórias. Para o presente estudo a codificação das narrativas foi realizada pela primeira autora e por outras duas graduandas treinadas na teoria e na prática por uma especialista no uso deste instrumento. A versão utilizada neste estudo foi a traduzida para o português e utilizada por Semensato (2009). (5) Entrevista sobre a relação mãe-bebê (M. Bortolini \& C. A. Piccinini, personal communication, 2012): trata-se de uma entrevista estruturada, realizada de forma semidirigida, construída para investigar a relação mãe-bebê, e foi baseada nos eixos de afeto e superproteção da Parental Bonding Instrument- PBI (Parker et al., 1979). As respostas foram examinadas por análise de conteúdo qualitativa (Laville \& Dionne, 1999), com base nos dois eixos da PBI, 
afeto e a superproteção e nos próprios dados, o que permitiu identificar indicadores atuais da relação mãe-bebê.

\section{Resultados e Discussão}

Os resultados foram apresentados como relato clínico separadamente para cada caso com destaque para os seguintes tópicos: caracterização do caso, que abordou dados sociodemográficos e de configuração das famílias, e os dados referentes ao Parental Bonding Instrument/PBI; representações de apego da mãe, onde se descreveu os achados do Attachment Script Assessment/ASA; relação mãebebê, onde foram destacados o apego mãe-filho através do Attachment Q-Sort/AQS e os aspectos relacionais da díade relatados pela mãe na Entrevista sobre a relação mãe-bebê; e discussão do caso, onde se apresentou uma compreensão dinâmica do caso, relacionando todas as informações disponíveis.

\section{Caso 1: Paula e Paola}

Paula (37 anos) era casada há três anos com Pedro (35 anos), e mãe de sua primeira filha Paola ( 2 anos e 1 mês), cuja gestação foi muito planejada. A gestação e o parto foram períodos tranquilos em termos clínicos, mas permeados pela presença de algumas ansiedades relacionadas ao bem-estar futuro da filha. Os primeiros dias com a filha foram "muito difíceis", especialmente pela presença da sua mãe em casa, a qual estava auxiliando nos cuidados com a neta diariamente. Paula tinha uma relação difícil com a mãe, pois percebia a mãe como indisponível para dialogar, implicante com o seu marido, além de intrusiva no cuidado com a neta. Essa relação mais difícil com a mãe parecia estar relacionada à história de vinculação familiar. Paula referiu que não conheceu o pai biológico e que aos seis anos de idade teve um padrasto, com o qual sempre foi distante devido às imposições da mãe para se relacionar bem com ele e ter de chamá-lo de pai, assim como pelo jeito rígido de ser da sua mãe. Ainda destacou que conseguia lidar um pouco melhor com essa história pelo fato de fazer terapia, mas que ainda era difícil pensar sobre a "falta de sensibilidade, a educação muito rígida e a pouca afetividade" recebida pela mãe. Quanto à percepção de Paula sobre o cuidado que teve na infância ( $\mathrm{PBI}$ ), esse foi referido como um cuidado de controle sem afeto, ou seja, baixo em afeto e alto em superproteção.

Em relação ao marido, Paula mencionou que o apoio dele "foi querer ter filho e compartilhar com ela algumas ansiedades". Quanto às consultas médicas, exames e todas as situações relacionadas à gravidez, Paula as fazia sozinha. Em relação a essas ausências, Paula 
falou em um primeiro momento não ter sentido a falta do marido, porém, ao longo da entrevista referiu que era difícil lidar com essa ausência e que era uma falha de cuidado com a filha.

Com relação às representações de apego da mãe com sua própria mãe, as narrativas (ASA) elaboradas por Paula se caracterizam pela ausência do fenômeno de base segura, tanto nas histórias que incitam representações de apego das relações com os cuidadores, quanto das que incitam representações mentais de apego da relação romântica ${ }^{3}$. As narrativas foram caracterizadas pela ausência de trocas emocionais entre os personagens, evidenciando falta de sensibilidade e de disponibilidade de conforto, principalmente após uma crise. Paula também criou narrativas que relatam eventos com falta de conteúdos emocionais e detalhes de interação, e os personagens não apresentavam interação emocional. Não houve resolução da crise e do desconforto elaborado na narrativa, e nenhum auxílio do personagem que representa a base segura em minimizar as emoções negativas. Nas narrativas envolvendo relações românticas houve ausência de reciprocidade e falta da reafirmação do amor frente a uma crise. Assim, a análise evidenciou ausência de conteúdos de base segura, indicando a ausência de representações de apego seguro.

Sobre a relação de Paula com sua filha, foi evidenciada uma pontuação baixa para segurança ( $A Q S=0,244)$, sugerindo que a filha tendia a não perceber a mãe como uma base segura, ou seja, não percebia a mãe como uma fonte de conforto e proteção, bem como tendia a não sentir incentivo da autonomia para explorar o desconhecido. Logo, a relação da díade, poderia ser compreendida como uma relação com pouca sensibilidade da mãe para atender necessidades emocionais da filha.

Durante a entrevista sobre a relação mãe-filha, Paula referiu que a relação com a filha era boa, mas que dependia muito do dia: "À noite quando eu chego em casa, ela tá sempre muito feliz, querendo ver a gente. Mas tem aquela coisa do cansaço, ela quer atenção, então a relação depende muito de como tá o humor dela e o meu. Eu procuro ter paciência, mas nem sempre a gente tem" ${ }^{4}$. Ela disse: "Paola sempre quer mais minha presença". Paula também referiu preocupação de não "mimar" a filha: "Eu tenho uma preocupação de não mimar muito no sentido da criança não imaginar que o mundo é um conto de fadas". Esse 'não mimar' estava muito relacionado aos "nãos" para a filha: "Eu não faço muito as vontades dela porque eu fico achando que ela vai achar que sempre as coisas tem que acontecer do jeito que ela quer". Frente às proibições, a filha normalmente não aceitava muito bem: "Ela fica muito brava comigo, chora, fica sentida". Assim como em relação aos limites, vinha sendo uma fase complicada, pois a filha não aceitava com facilidade as ordens da mãe. Nessas situações, Paula tentava distraí-la: "Com 
criança é bem básico: tu muda o foco da atenção, tu vai fazer outra coisa".

Quando questionada sobre as facilidades e dificuldades de compreender a filha, Paula mencionou que as questões não emocionais eram mais fáceis: "As questões básicas de sono, fome, banho são as mais fáceis de compreender". E o que era considerado mais difícil: "É a compreensão de uma brincadeira, de uma atenção que ela precise". Estar disponível emocionalmente nesses momentos não parecia ser fácil para Paula, principalmente devido ao seu próprio estado emocional: "Eu não tenho muita disponibilidade emocional, é uma coisa prazerosa atender ela, mas como eu lido emocionalmente com as coisas, fico muito estressada e não consigo estar muito disponível para ela". Por outro lado, Paula destacou que "Não é nem que eu faço pra ela se sentir amada é uma coisa do amor".

Quanto ao crescimento e a aquisição de novas habilidades, Paula mencionou: "Ela tá entendendo mais, ela acaba virando mais uma companhia do que alguém só pra se cuidar". Essa questão da filha ser uma "parceria" estava relacionada ao fato de que Paula não tinha muitas amigas no atual momento: "Eu fiquei muito sem amigas nessa fase, porque tem muitas amigas que não tem filhos. Eu quase não saio à noite, mas o outro [marido] sai. Então a Paola é quase a minha melhor amiga".

Em relação a outras pessoas que cuidavam da filha, Paula sentia confiança apenas na babá e em uma tia. Quanto ao marido, Paula disse que era mais tranquilo agora do que quando a filha era menor, mas mesmo assim não sentia confiança em deixar a filha com ele por longos períodos. Paula se percebia como dando muita proteção, principalmente pelo fato de restringir com quem a filha convivia e por ela não conseguir deixar a filha na creche, pois se sentia "aflita", porém achava que: "Eu não sinto a necessidade de mudar isso da creche, porque essa dinâmica atende nossas necessidades".

\section{Discussão do caso}

A partir dos relatos de Paula foi identificado que algumas necessidades emocionais dela não foram compreendidas e atendidas pelos seus próprios cuidadores. O motivo de Paula não ter conhecido o seu pai biológico não foi revelado nas entrevistas, porém, essa falta, parece que deixou um registro emocional negativo de uma figura importante de vinculação (Ainsworth, 1989). Figura essa que foi "substituída" por um padrasto que não correspondeu às suas necessidades emocionais de vinculação. Essa vivência com o padrasto, que foi experienciada de forma negativa, especialmente pela maneira da mãe lidar com a situação, iniciou quando Paula ainda estava em processo de formação do self, aos seis anos de idade, 0 
que provavelmente contribuiu para o desenvolvimento de um possível self não merecedor de amor, não compreendido, não atendido em suas demandas emocionais, bem como de figuras de vinculação não sensíveis, não disponíveis emocionalmente, e não provedoras de conforto e de incentivo da autonomia (Bowlby, 1998).

Ao encontro de tais aspectos, pode-se pensar que estas representações foram acentuadas visto que a mãe também foi pouco afetiva, amável e sensível, além de ter sido ausente e rígida. Diante disso, Paula vivenciou com todos os seus principais cuidadores relações que pouco the atenderam emocionalmente. Desta forma, mesmo sendo possível estabelecer padrões de apego distintos com cuidadores diferentes (Main, Kaplan \& Cassidy, 1985), parece que Paula não teve uma figura de cuidado que pudesse ter se configurado como um fator de proteção frente às vivências negativas. Tais vivências podem ter contribuído muito para a elaboração de representações de Paula de apego sem base segura (Waters \& Rodrigues-Doolabh, 2001).

A partir dessas vivências, as representações de Paula parecem ter refletido na ausência do fenômeno de base segura nas suas representações de apego, o que sugere que ela tendia a sentir que não teria auxílio diante de suas necessidades, bem como não teria pessoas sensíveis para atender as suas demandas emocionais. Tais características foram evidenciadas nas falas de Paula, quando referiu que sentia que não tinha pessoas disponíveis para conversar e atendê-la emocionalmente. Diante desse contexto, parece que a estratégia que Paula desenvolveu para lidar com essas representações das figuras de vinculação foi pensar que não precisava de ajuda e que se sentia bem sozinha. Entretanto, houve certa ambivalência nos seus relatos, como por exemplo, quando fez referência às queixas sobre as ausências do marido, a dificuldade da mãe lhe compreender e a falta de proximidade das amigas. Com base nisto, pode-se pensar como hipótese que Paula tinha um padrão de apego inseguro evitativo. Segundo Ainsworth (1989), pessoas com tendência a ter apego inseguro evitativo, tendem a lidar racionalmente com suas necessidades emocionais, principalmente, reafirmando para si que são suficientes emocionalmente.

Além das representações de apego das vivências infantis, as representações de apego das relações românticas de Paula, também apresentaram ausência de conteúdo de base segura. Neste sentido, pessoas que têm vivências de vinculação negativas na sua infância, teriam tendência a escolher parceiros que corresponderiam a uma imagem semelhante frente as suas necessidades emocionais (Waters $\&$ Rodrigues-Doolabh, 2004). Por outro lado, para outros padrões de apego da infância seriam moderadamente relacionados aos da vida amorosa e a relação amorosa poderia auxiliar na elaboração de um novo padrão de apego (Cowan \& Cowan, 2001; Waters, Weinfeld \& 
Hamilton, 2000). Em relação ao marido de Paula, notou-se que ela apresentava várias queixas, porém estas eram relativizadas em vários momentos. Estas eram relacionadas à falta de disponibilidade do marido de cuidar da filha, de ele sair à noite, bem como de não acompanhá-la nos cuidados com a filha. Apesar de Paula mencionar que o marido era afetivo com ela, também esteve presente nos relatos o desejo de ter um marido mais presente, uma relação de mais companheirismo, de mais reciprocidade e responsabilidade conjunta na criação da filha. Dessa forma, pode-se pensar que Paula tinha com o marido uma relação que pouco a atendia emocionalmente, assim como aconteceu na sua infância.

Acerca desta hipótese, é importante referir que, segundo Main (2000), o padrão de apego não seria totalmente definido na infância, visto que todos seriam suscetíveis a vivenciar experiências favoráveis e desfavoráveis, e consequentemente viver reelaborações futuras, que poderiam alterar os estados mentais em relação ao apego. Apesar disso, pode-se pensar que Paula apresentou uma continuidade destes padrões de apego, especialmente pelas características das suas relações, em particular a filial, com Paola, e conjugal, com Pedro.

Mães que tiveram uma história sem base segura com seus cuidadores tenderiam a ter uma história de vinculação parecida com os seus próprios filhos (Bost et al., 2006; Veríssimo, Monteiro, Vaughn, Santos \& Waters, 2005). No caso de Paula, ela fez menção sobre o desejo de ser uma mãe mais presente, afetiva, paciente e disponível emocionalmente para a filha. Porém, em muitos momentos ela não conseguia fazer o que se propunha. $O$ fato de que Paula se dizia diariamente estressada, evidencia que ela não vinha apresentando recursos emocionais para lidar com as demandas do seu trabalho, fato este que também repercutia na sua relação com a filha. A ausência de recursos internos esta relacionada aos aspectos contextuais (Main, 2000; Miljkovitch, Pierrehumbert \& Halfon, 2007), mas também à história de vinculação com os cuidadores infantis, bem como com a relação conjugal, podendo gerar, por exemplo, indisponibilidade emocional para atender as necessidades dos filhos (Veríssimo, Monteiro, Vaughn, Santos \& Waters, 2005).

Tais aspectos da relação mãe-filha também foram evidenciados no comportamento de apego inseguro da filha que tendem a refletir os comportamentos da mãe. Mães pouco sensíveis, não disponíveis para atender e compreender as demandas emocionais dos filhos tenderiam a ter filhos com comportamentos de apego característicos de um apego inseguro (Veríssimo, Monteiro, Vaughn, Santos \& Waters, 2005). A relação Paula-Paola parecia permeada pela falta de sensibilidade materna, falta de conforto, de disponibilidade emocional, de presença e de afetividade. Apesar destas características relacionais com a mãe, um fator de proteção para 
Paola era a relação afetiva que ela tinha com a sua babá, a qual, segundo Paula, era 'extremamente sensível'. De acordo com a literatura, creches com educadoras sensíveis ou babás sensíveis constituem-se como fatores protetores de um apego seguro (Belsky, 2009).

Os resultados desta díade indicaram semelhança no padrão de cuidado que Paula recebeu de sua mãe e o padrão de relacionamento que ela estabeleceu com a sua filha. Isto corrobora a literatura sobre a transmissão intergeracional dos padrões de apego, de modo que os padrões de apego de uma geração tendem a passar para outra, especialmente pelas representações de apego e o tipo de relação estabelecida (Bowlby, 1998; van Ijzendoorn \& BakermansKranenburg, 1997). Neste caso, pode-se pensar que houve uma tendência do padrão de apego inseguro e de uma relação menos sensível se repetir entre as gerações.

\section{Caso 2: Beatriz e Bruna}

Beatriz ( 32 anos) era casada com Bernardo ( 33 anos) há cinco anos, e mãe de sua primeira filha, a Bruna ( 2 anos). A decisão do casal sobre a gravidez esteve relacionada com o fato da relação conjugal ter ficado "vazia". Dessa forma, decidiram ter um filho e Beatriz logo engravidou. A gestação de Beatriz em termos físicos e emocionais foi "muito tranquila", bem como o parto. Já em relação aos primeiros dias e meses após o nascimento, Beatriz referiu que foi difícil emocionalmente para ela, especialmente por ter ficado ansiosa e preocupada com os cuidados para com a filha recém nascida. Sentimentos de sobrecarga também foram referidos por Beatriz, visto que o marido trabalhava fora de casa durante toda a semana e ela assumia todas as atividades da casa e com a filha. Ressalta-se ainda, que Bruna foi para a creche nos primeiros meses de vida, sendo essa uma decisão do casal.

No tocante ao seu papel de mãe, ela lembrou que era parecida com a sua própria mãe pelo fato de ser pouco afetiva, e que seguia muito o modelo da avó quanto à organização e de querer realizar tudo corretamente. Quanto à percepção do cuidado recebido de sua mãe $(\mathrm{PBI})$, Beatriz o percebia como um cuidado de controle sem afeto, ou seja, um cuidado com muita superproteção e pouco afeto. O pai de Beatriz faleceu quando ela era muito pequena e, por isso, a mãe trabalhou muito fora de casa e a avó foi quem cuidou dela.

Com relação à representação de apego (ASA), Beatriz apresentou narrativas com representações de apego sem base segura, tanto em relação aos seus cuidadores, quanto à relação romântica. As narrativas elaboradas por Beatriz foram caracterizadas pela ausência de trocas emocionais, ausência da percepção dos sentimentos do 
personagem em crise, bem como ausência de conforto. Poucos detalhes foram fornecidos nas narrativas, sendo apenas caracterizadas pela descrição de uma sequência de eventos. Verificou-se narrativas sem resolução da crise, ausência de conteúdos de reafirmação do amor e de reciprocidade, indicando a ausência de representações de apego seguro.

Sobre a relação mãe-filha, de Beatriz e Bruna, os resultados revelaram pontuação baixa para os comportamentos de segurança $(\mathrm{AQS}=0,23)$. I sso sugere que a filha podia não sentir sua mãe como uma fonte de conforto e proteção frente as suas necessidades emocionais, e de confiança para explorar o mundo, indicando uma tendência de Beatriz exercer pouco a função de base segura para a sua filha. Os relatos de Beatriz mostraram que seu jeito podia estar muito relacionado com o da sua própria mãe: "Acho que tem muito da falta de afeto da minha criação, eu acho que eu não sou tão afetuosa o quanto eu gostaria de ser. Eu sei que supro todas as necessidades básicas dela, mas a afetividade eu não sei...". Beatriz afirmou com certa frustração que esse modo de ser estava muito relacionado com o modo que ela foi educada: "Queria não ser eu. Vejo que meu marido é diferente, ele senta e conversa com ela e eu sou mais prática, eu quero muito rápido. Daí eu penso de como eu fui criada".

Quando Beatriz relatou o que era mais difícil na relação com a filha, ela reconheceu que eram as questões emocionais: "A pressão do sentimental dela para mim é complicado. Ela andava num período que chorava e eu não sabia o que eu fazia ou o que era. $O$ emocional é o mais complicado". A relação também foi dificultada, segundo a visão de Beatriz, pelo temperamento forte da filha e pelo jeito dela lidar com esse temperamento. Beatriz disse que não gostaria de se chatear e se cobrar tanto: "Às vezes penso: 'Ela podia me entender, eu me desgasto tanto', mas também tem muito de eu me exigir, ficar me cobrando para fazer tudo certo".

Beatriz também destacou que não conseguia estabelecer limites adequados e que precisava fornecer mais explicações para a filha: "Acho que eu não consigo explicar o que acontece quando eu digo um 'não', eu tenho essa coisa de não querer perder tempo, de fazer tudo rápido". Beatriz também sentia que tinha pouco controle sobre a filha e desejava ter mais: "Eu queria ter mais, porque às vezes ela me domina. Mas a questão está em mim, eu tenho que ser mais confiante. Eu tenho que saber conversar com calma e perder mais tempo com isso, não querer ser rápida e objetiva".

Embora Beatriz se descrevesse como uma 'boa mãe', ela relatou que poderia fazer algumas coisas diferentes: "Acho que eu deveria conversar mais com ela, explicar mais as coisas, aprender a dar um limite melhor". Beatriz referiu também: "Acho que o problema é que a gente não se compreende, mas acho que ela se sente amada, 0 
problema mesmo é na relação". Quando a filha estava chateada, disse que gostaria de dar mais força para ela: "Eu até fico chateada, quero dar força pra ela, mas às vezes não consigo, tenho que contar até 10 , respirar para atender ela". Sobre o incentivo da autonomia achava que conseguia lidar bem ao deixar a filha na creche e com as avós. Entretanto, também afirmou que tendia a fazer a filha dependente dela: "Eu quero fazer as coisas com pressa, eu acabo fazendo tudo, daí ela não faz".

\section{Discussão do caso}

A experiência de Beatriz com a sua mãe na infância não foi muito detalhada, porém, pode-se inferir que era uma relação com baixa afetividade, na qual o carinho e o conforto não eram muito presentes. Também se percebeu em Beatriz um padrão de organização e de exigência consigo e com o mundo, o qual podia estar relacionado com a criação recebida da avó. Isto poderia estar associado a uma maior insegurança e ansiedade para lidar com as situações, visto que tudo precisava estar sempre certo ou de acordo com ela. A perda do pai aos seis anos foi mencionada, sendo que uma das consequências pode ter sido o fato de "ter que se virar sozinha", pois a mãe ficou mais ausente por ter que trabalhar. De acordo com Waters et al. (2000), a vivência da perda de um cuidador principal e um cuidado pouco afetivo e indisponível de um outro cuidador estaria associada a representações de apego sem base segura. Esta ausência de base segura pode ser identificada na fala de Beatriz ao referir em diversos momentos que precisava dar conta da vida sozinha.

De acordo com Mikulincer, Hirschberger, Nachmias e Gillath (2001), a representação de apego seria uma representação de si, do outro e do padrão de interação. Estas representações podem ser compreendidas nas percepções de Beatriz sobre si, especialmente quanto ao desejo de querer ser mais afetiva com a filha e com as pessoas de maneira geral, de não querer se cobrar e exigir tanto, de ser mais tranquila e não achar que precisava deixar tudo pronto e organizado, bem como o desejo de saber lidar emocionalmente consigo e com o lado emocional da filha.

Quanto à relação com o marido, foram fornecidas muitas informações, mas apareceram alguns sentimentos de solidão de Beatriz nos primeiros meses da filha, sobrecarga por dar conta da filha, da casa e do trabalho, sem muita participação do marido. Dessa forma, pode-se pensar que a escolha de companheiro pode ter sido também influenciada pelas representações iniciais em relação aos cuidadores, visto que Beatriz escolheu um companheiro não muito disponível, até mesmo ausente. Esta relação vai em parte ao encontro de Sroufe et al. (2005), segundo o qual, a história de apego 
na infância estaria relacionada à predição da relação do casal quanto às expectativas de se sentir conectado ao outro, às atitudes de responsividade em relação ao outro, à capacidade de regulação emocional e à capacidade de mutualidade e empatia.

A partir dessas vivências, Beatriz apresentava representações de apego sem base segura quanto aos cuidadores e à relação romântica. As narrativas que ela elaborou foram caracterizadas pela ausência de conteúdo afetivo e emocional, falta de disponibilidade emocional de um para com o outro, ausência de trocas afetivas, falta de explicação e minimização da crise. Essas representações de apego explicitariam as vivências emocionais da infância com as figuras de vinculação, bem como com as suas relações românticas (Waters et al., 1998; Waters \& Rodrigues-Doolabh, 2001).

As representações de apego estariam associadas ao tipo de relação que esta estabelece com o seu filho (Waters et al., 1998). Mães com representação de apego sem conteúdo de base segura seriam menos sensíveis aos sinais de seus filhos (Bost et al., 2006; Veríssimo, Monteiro, Vaughn, Santos \& Waters, 2005). Diante disso, cabe destacar que Beatriz percebia a própria falta de recursos emocionais para atender emocionalmente a filha, especialmente em estar próxima da filha, bem como em reconhecer os sentimentos dela. Além disso, a filha gerava sentimentos de raiva, de culpa e de que não era uma boa mãe. Estes dados vão ao encontro da literatura sobre a ausência de recursos emocionais maternos, muito relacionados às representações de apego sem base segura, que tem muito impacto na relação com os filhos (Bost et al., 2006; Veríssimo et al., 2005). Por outro lado, também poder-se-ia pensar que o temperamento 'mais forte' da filha, também tenderia a influenciar a baixa disponibilidade emocional da mãe para atendê-la. Conforme Laible (2004), o temperamento, por causar diferentes reações nos cuidadores, afetando a relação mãe-bebê e consequentemente influenciando o padrão de apego da criança. Logo, seria importante considerar a sua mutualidade das relações.

Apesar de Beatriz apresentar consciência das suas dificuldades na relação com a filha e as consequências disso, nos seus relatos ficou claro que não conseguia modificar esse padrão de relacionamento. De acordo com van Ijzendoorn e Bakermans-Kranenburg (1997), a resignificação de um padrão de apego infantil poderia acontecer por representações de apego de relações atuais, as quais exerceriam o papel de base segura, e tenderiam a influenciar, por exemplo, os novos comportamentos parentais. Entretanto, parecia que Beatriz não tinha essas novas relações que possibilitariam a resignificação do seu padrão de apego. Além destes aspectos, também poder-se-ia pensar que os sintomas de ansiedade de Beatriz poderiam contribuir para uma baixa qualidade da relação com a filha, pela diminuição da sensibilidade e uma maior intrusividade e vigilância (Moehler et al., 
2006; Kaitzaet al., 2010). Apoiado na literatura é plausível pensar que as vivencias e representações de apego de Beatriz, estavam associadas ao tipo de relação que estabelecia com a filha e aos comportamentos de apego inseguro da filha, cujas relações foram encontradas em estudos empíricos (Huth-Bocks, Levendosky, Bogat \& von Eye, 2004; Mikulincer, Hirschberger, Nachmias \& Gillath, 2001; Waters \& Waters, 2006; van Ijzendoorn \& Bakermans-Kranenburg, 1997).

\section{Considerações finais}

Os resultados do presente estudo revelam evidencias sobre a associação entre experiências sem base segura das mães e apego inseguro do filho. Trata-se de evidencias com base em dados qualitativos a partir de dois casos que estão na direção do que sugere a literatura, ou seja, uma relação entre as experiências da mãe com seus cuidadores, as representações maternas de apego, a relação com o filho e o apego desse filho. Em outro artigo (Bortolini \& Piccinini, 2015), os autores já haviam apresentado evidencias de que experiências de base segura das mães estariam associadas ao apego seguro dos filhos. Neste sentido, tanto o estudo anterior, como o presente, apontam que as vivências infantis com os cuidadores e com o companheiro na vida adulta, e as representações de apego decorrentes, impactam a relação mãe-filho e o comportamento de apego da criança (Bost et al., 2006; Mikulincer, Shaver, Sapir-Lavid, \& Avihou-Kanza, 2009; Veríssimo, Monteiro, Vaughn, Santos, \& Waters, 2005; van Ijzendoorn \& Bakermans-Kranenburg, 1997).

Contudo, como se trata de evidencias baseadas em casos, novos estudos se fazem necessários para compreender a extensão destes achados, mesmo que estejam corroborando com a teoria do apego (Bowlby, 1989). Soma-se a isto o fato de que os instrumentos foram respondidos apenas pela mãe, com ausência de triangulação de outras fontes (Stake, 2006), bem como, eventuais dificuldades das mães na elaboração das narrativas e mesmo a desejabilidade social materna ao se referir sobre a relação com o filho, podem ter afetado os resultados.

Apesar destas eventuais limitações, os resultados corroboram com a ideia de que as experiências das mães com os seus cuidadores tende estar associada à relação atual mãe-filho. Trata-se de um estudo com uma abordagem predominantemente qualitativa o que possibilitou ao leitor a compreensão da relação entre as vivências maternas, as representações de apego maternas, a relação mãe-filho, e o apego do filho. Tais associações são encontradas na literatura, mas predominantemente em estudos quantitativos, os quais nem sempre 
permitem compreender as particularidades das dinâmicas dessas associações.

Os achados endossam a importância de se promover ações de saúde emocional que sensibilizem as mães e pais, quanto à importância das relações iniciais com seu bebê, tendo em vista que os padrões de apego tem o potencial de deixar marcas importantes em todo o desenvolvimento humano. Isto é particularmente relevante em situações em que existam dificuldades na relação pai-mãe-bebê, o que poderá marcar negativamente as vivências iniciais das crianças, levando ao estabelecimento de representações de apego inseguro nestas crianças e consequentemente nas relações futuras com seus próprios filhos.

\section{Referências}

Ainsworth, M. D. S. (1989). Attachments Beyond Infancy. American Psychologist, 44(4), 709-716.

Ainsworth, M. S., Blehar, M. C., Waters, E., \& Wall, S. (1978). Patterns of attachment: A psychological study of the Strange Situation. Hillsdale, NJ: Erlbaum.

Barbisan, J. W. (1993). Qualidade do brinquedo simbólico na infância: contribuições do apego mãe-criança. (Tese de doutorado, não publicada). Universidade Federal do Rio Grande do Sul, Rio Grande do Sul, Brasil.

Bortolini, M. \& Piccinini, C. A. (2015). Transmissão Intergeracional do Apego Seguro: Evidências a Partir de Dois Casos. Revista Psicologia em Estudo, 20(2), 247-259.

Belsky J. (2009). Creche na primeira infância e segurança do apego mãe-bebê. In R. E. Tremblay, M. Boivin, \& R. De V. Peters (Eds), Enciclopédia sobre o Desenvolvimento na Primeira Infância [on-line] (pp. 1-5). Retrieved from http://www.enciclopedia-crianca.com/apego/segundoespecialistas/creche-na-primeira-infancia-e-seguranca-doapego-mae-bebe.

Bost, K. K., Shin, N., Mcbride, B. A., Brown, G. L., Vaughn, B. E., Coppola, G., Verissimo, M., ... Korth, K. (2006). Maternal secure base scripts, children's attachment security, and mother - child narrative styles. Attachment \& Human Development, 8(3), 241-260. doi: 10.1080/14616730600856131

Bowlby, J. (1960). Ethology and the development of object relations. International journal of Psycho-analysis, 41, 313-317.

Bowlby, J. (1988/1989). Uma base segura: aplicações clínicas da teoria do apego. Porto Alegre: Artes Médicas.

Bowlby, J. (1979/1997). Formação e rompimento dos laços afetivos. São Paulo: Martins Fontes. 
CRESCI (2012). Ficha de dados demográficos da família. Instrumento não publicado. Instituto de Psicologia, Universidade Federal do Rio Grande do Sul.

Cowan, P., \& Cowan, C. P. (2001). A couple perspective on the transmission of attachment patterns. In C. Clulow (Ed.). Adult Attachment and couples psychotherapy (pp. 61-82). London/New York: Routledge.

Fonagy, P. (1999). Transgenerational consistencies of attachment: A new theory. Revista de Psicoanalisis, 3. Retrieved from http://psychematters.com/papers/fonagy2.htm

Fonagy, P., Steele, H., \& Steele, M. (1991). Maternal representations of attachment during pregnancy predict the organization of infant-mother attachment at one year of age. Child Development, 62, 891-905.

Gomes, V. F. (2007). Representações mentais de apego e percepção de práticas parentais por jovens adultas. (Tese de doutorado, não publicada). Universidade Federal do Rio Grande do Sul, Rio Grande do Sul, Brasil.

Grossmann, K., \& Grossmann, K. E. (2011). O impacto do apego à mãe e ao pai e do apoio sensível à exploração nos primeiros anos de vida sobre o desenvolvimento psicossocial das crianças até o início da vida adulta. In $M$. van Ijzendoorn (Ed.), Enciclopédia sobre o desenvolvimento da primeira infância ( $p p$. 1-8). Holanda: Leiden University.

Hauck S., Schestatsky S., Terra L., Knijnik L., Sanchez P., \& Ceitlin L. H. F. (2006). Adaptação transcultural para o português brasileiro do Parental Bonding Instrument (PBI). Revista de Psiquiatria, 28(2), 162-168.

Huth-Bocks, A. C., Levendosky, A. A., Bogat, G. A., \& von Eye, A. (2004). The impact of maternal characteristics and contextual variables on infant-mother attachment. Child Development, 75, 480-496.

Kaitza, M., Maytala, H. R., Devora, N., Bergmana, L., \& Mankuta, L. (2010). Maternal anxiety, mother-infant interactions, and infants' response to challenge. Infant Behavior \& Development 33, 136- 148. doi: 10.1016/j.infbeh.2009.12.003.

Laible, D. (2004). Mother-Child Discourse in Two Contexts: Links With Child Temperament, Attachment Security, and Socioemotional Competence. Developmental Psychology, 40(6), 979-992.

Leekers, E. M. (2011). Maternal Sensitivity During Distressing Tasks: A Unique Predictor of Attachment Security. Infant Behavior and Development, 34(3), 10.1016/j.infbeh.2011.04.006

443-446. doi:

Main, M (1991). Metacognitive knowledge, metacognitive monitoring and singular (coherent) vs multiple (incoherent) models of 
attachment: findings and directions for future research. In C. M. Parkes \& P. Marris (Eds.), Attachment across the life cicle (pp. 127-159). London: Routledge.

Main, M. (2000). The organized categories of infant, child and adult attachment: flexible vs. inflexible attention under attachmentrelated stress. Journal of the American Psychoanalytic Association, 48(4), 1055-1127.

Main, M., Kaplan, N., \& Cassidy, J (1985). Security of infancy, childhood and adulthood: A move to the level of representation. In I. Bretherton, \& E. Waters (Orgs.), Growing points of attachment theory and research (pp. 66-106). Chicago: University of Chicago Press.

Mikulincer, M., Hirschberger, G., Nachmias, O., \& Gillath, O (2001). The Affective Component of the Secure Base Schema: Affective Priming With Representations of Attachment Security. Journal of Personality and Social Psychology, 81(2), 305-321.

Miljkovitch, R., Pierrehumbert, B., \& Halfon, O. (2007). Three-yearsolds' attachment play narratives and their association with internalizing problems. Clinical psychology and psychotherapy, 14, 249-57.

Moehler, E., Brunner, R., Wiebel, A., Reck, C., \& Resch, F. (2006). Maternal depressive symptoms in the postnatal period are associated with long-term impairment of mother-child bonding. Archives of Women's Mental Health, 9, 273-278.

Muzzio, E. G., Muñoz, M. M., \& Santelices, M. P. (2008). Efectividad de lãs intervenciones em apego com infância vulnerada y en riesgo social: um desafío prioritario para Chile. Terapia Psicológica, 26(2), 241-51. doi: 10.4067/S071848082008000200010

Parker, G., Tupling, H., \& Brown, L. B. (1979). A Parental Bonding Instrument. British Journal of Medical Psychology, 52, 1-10.

Piccinini, C. A. et al (2012). "Impacto da creche no desenvolvimento socioemocional e cognitivo infantil: estudo longitudinal do sexto mês de vida do bebê ao final dos anos pré-escolares" - CRESCI (projeto não publicado). Universidade Federal do Rio Grande do Sul, Rio Grande do Sul, Brasil.

Semensato, M. R. (2009). Relações entre scripts de apego individuais e compartilhados em casais com um filho com autismo. (Dissertação de mestrado não publicada). Universidade Federal do Rio Grande do Sul, Rio Grande do Sul, Brasil.

Stake, R. E. (2006). Multiple case study analysis. New York: The Guilford Press.

Van IJ zendoorn, M. H. (1995). Of the Way We Are: On Temperament, Attachment, and the Transmission Gap: A Rejoinder to Fox. Psychological Bulletin, 117(3), 411-415. 
Van IJzendoorn, M. H., \& Bakermans-Kranenburg, M. J. (1997). Intergenerational transmission of attachment: A move to the contextual level. In L. Atkinson \& K. J. Zucker (Eds.), Attachment and psychopathology (pp. 135-170). New York: Guilford Press.

Veríssimo, M., Monteiro, L., Vaughn, B., Santos, A. J., \& Waters, H. (2005). Coordenação entre o modelo dinâmico interno da mãe e o comportamento de base segura dos seus filhos. Análise Psicológica, 2(23), 85-95.

Waters, E. (1987). Attachment behavior Q-Set (revision 3.0.). New York: State university of New York at Stony Brook.

Waters, H. S., \& Rodrigues-Doolabh, L. (2001). Are attachment scripts the building blocks of attachment representations? Narrative assessment of representations and the AAl. (Poster symposium presented at the Biennial Meetings of the Society for Research in Child Development). Minneapolis, EUA.

Waters, H. S., \& Rodrigues-Doolabh, L. (2004). Manual for decoding secure base narratives. (Unpublished manuscript). State University of New York at Stony Brook, Nova York.

Waters, H. S., Rodrigues, L. M., \& Ridgeway, D. (1998). Cognitive underpinnings of narrative attachment assessment. Journal of Experimental Child Psychology, 71, 211-234.

Waters, E., Weinfeld, N. S., \& Hamilton, C. E. (2000). The stability of attachment security from infancy to adolescent and early adulthood: general discussion. Child Development, 71(3), 703706.

Waters, H., \& Waters, E. (2006). The attachment working models concept: Among other things, we build script-like representations of secure base experiences. Attachment \& Human Development, 8(3), 185-197.

Wong, M., Bost, K. K., Shin, N, Veríssimo, M., Maia, J., Monteiro, L., ... Vaughn, B. E. (2011) Preschool children's mental representations of attachment: antecedents in their secure base behaviors and maternal attachment scripts. Attachment \& Human Development, 13(5), 489-502. 


\section{Endereço para correspondência \\ Marcela Bortolini}

Universidade Federal do Rio Grande do Sul - UFRGS

Rua Ramiro Barcelos, 2600, Santa Cecília, CEP 90035-003, Porto Alegre - RS, Brasil

Endereço eletrônico: bortolini.marcela@gmail.com

Cesar Augusto Piccinini

Universidade Federal do Rio Grande do Sul - UFRGS

Rua Ramiro Barcelos, 2600, Santa Cecília, CEP 90035-003, Porto Alegre - RS, Brasil

Endereço eletrônico: piccinini@portoweb.com.br

Recebido em: 29/03/2016

Reformulado em: 27/04/2017

Aceito em: 03/05/2017

\section{Notas}

* Doutoranda. Programa de Pós-graduação em Psicologia do Desenvolvimento. Universidade Federal do Rio Grande do Sul (UFRGS). Porto Alegre. Estado do Rio Grande do Sul. Brasil.

** Docente. Programa de Pós-graduação em Psicologia do Desenvolvimento. Universidade Federal do Rio Grande do Sul (UFRGS). Porto Alegre. Estado do Rio Grande do Sul. Brasil.

${ }^{1}$ Os nomes utilizados no presente estudo são fictícios para preservar a identidade dos participantes.

2 Detalhes desse estudo podem ser acessados na dissertação de mestrado da primeira autora do presente estudo, orientada pelo segundo autor, intitulada "Experiência da mãe com seus cuidadores e a relação atual mãe-bebê" defendida junto a PPG-Psicologia da XXX, em 2014. Disponível em: https: //sabi.ufrgs.br/F/GQKXQYVCY4A7QENXH3J NK1CS14TLV1F7V7PPF4NVX61RYA BYTS-28805? func $=$ find-acc\&acc_sequence $=007074832$

${ }^{3} \mathrm{Na}$ dissertação da qual deriva o presente estudo, encontram-se os detalhes das narrativas e das análises realizadas, que sustentam a classificação descrita nos dois casos aqui apresentados.

${ }^{4} \mathrm{Na}$ dissertação da qual deriva o presente estudo, encontram-se diversos outros relatos que não são aqui apresentados devido às restrições de espaço. Por esta razão as vinhetas também foram editadas, excluindo-se aspectos que não eram fundamentais para a sua compreensão.

Este artigo de revista Estudos e Pesquisas em Psicologia é licenciado sob uma Licença Creative Commons Atribuição-Não Comercial 3.0 Não Adaptada. 